\title{
Clinical and genetic characterization of congenital hyperinsulinism in Spain
}

\author{
R Martínez1,", C Fernández-Ramos 2,", A Vela, T Velayos', A Aguayo', I Urrutia1, \\ I Rica ${ }^{3}$ and L Castaño ${ }^{1}$ on behalf of the Spanish Congenital Hyperinsulinism Group ${ }^{+}$ \\ ${ }^{1}$ Endocrinology and Diabetes Research Group, BioCruces Health Research Institute, Cruces University \\ Hospital, CIBERDEM, CIBERER, UPV-EHU, Barakaldo, Spain, ²Pediatric Endocrinology Section, Basurto \\ University Hospital, BioCruces Health Research Institute, UPV/EHU, Bilbao, Spain, ${ }^{3}$ Pediatric \\ Endocrinology Section, Cruces University Hospital, BioCruces Health Research Institute, CIBERDEM, \\ CIBERER, UPV/EHU, Barakaldo, Spain \\ *(R Martínez and C Fernández-Ramos contributed equally to this work) \\ ${ }^{\dagger}$ (Details of the Spanish Congenital Hyperinsulinism Group are given in the \\ acknowledgements section)
}

Correspondence should be addressed to L Castaño

Email

Icastano@osakidetza.net

\begin{abstract}
Context: Congenital hyperinsulinism (CHI) is a clinically and genetically heterogeneous disease characterized by severe hypoglycemia caused by inappropriate insulin secretion by pancreatic $\beta$-cells.

Objective: To characterize clinically and genetically $\mathrm{CHI}$ patients in Spain.

Design and methods: We included 50 patients with $\mathrm{CHI}$ from Spain. Clinical information was provided by the referring clinicians. Mutational analysis was carried out for KCNJ11, ABCC8, and GCK genes. The GLUD1, HNF4A, HNF1A, UCP2, and $H A D H$ genes were sequenced depending on the clinical phenotype.

Results: We identified the genetic etiology in 28 of the $50 \mathrm{CHI}$ patients tested: 21 had a mutation in $\mathrm{K}_{\text {ATP }}$ channel genes (42\%), three in GLUD1 (6\%), and four in GCK (8\%). Most mutations were found in ABCC8 (20/50). Half of these patients (10/20) were homozygous or compound heterozygous, with nine being unresponsive to diazoxide treatment. The other half had heterozygous mutations in $A B C C 8$, six of them being unresponsive to diazoxide treatment and four being responsive to diazoxide treatment. We identified 22 different mutations in the $\mathrm{K}_{\text {ATP }}$ channel genes, of which ten were novel. Notably, patients with $A B C C 8$ mutations were diagnosed earlier, with lower blood glucose levels and required higher doses of diazoxide than those without a genetic diagnosis.

Conclusions: Genetic analysis revealed mutations in $56 \%$ of the $\mathrm{CHI}$ patients. $A B C \mathrm{C} 8$ mutations are the most frequent cause of $\mathrm{CHI}$ in Spain. We found ten novel mutations in the $\mathrm{K}_{\text {ATP }}$ channel genes. The genetic diagnosis is more likely to be achieved in patients with onset within the first week of life and in those who fail to respond to diazoxide treatment.
\end{abstract}

\section{Introduction}

Congenital hyperinsulinism (CHI) is the most frequent cause of persistent hypoglycemia in infancy. It is a rare genetic disorder characterized by severe hypoglycemia caused by inappropriate insulin secretion by pancreatic $\beta$-cells $(1,2)$.

$\mathrm{CHI}$ is a heterogeneous disease with differences in clinical presentation, histology, genetics, and response to treatment. To date, it has been associated with defects in nine genes. However, the genetic basis is only known

www.eje-online.org DOI: 10.1530/EJE-16-0027
() 2016 European Society of Endocrinology Printed in Great Britain in approximately $45-55 \%$ of patients affected by $\mathrm{CHI}$; hence, other mechanisms of the disease need to be determined $(3,4,5)$. The most frequent known causes of $\mathrm{CHI}$ are recessive or dominant inactivating mutations in the $A B C C 8$ and $K C N J 11$ genes, coding for SUR1 and Kir6.2 subunits of the ATP-dependent potassium channel $\left(\mathrm{K}_{\mathrm{ATP}}\right)$. Other less frequent causes are mutations in glutamate dehydrogenase (GLUD1), glucokinase (GCK), and short-chain L-3-hydroxyacyl CoA dehydrogenase

Published by Bioscientifica Ltd 
(HADH) genes, as well as in the SLC16A1, HNF4A, HNF1A, or UCP2 genes $(2,6)$.

The majority of patients with recessive $A B C C 8$ or KCNJ11 mutations are medically unresponsive to diazoxide treatment, whereas variable phenotypes and response to treatment have been reported for those with dominant ABCC8 or KCNJ11 mutations (7, 8, 9, 10). GLUD1 mutations are associated with mild-to-moderate hyperammonemia, mild hypoglycemia, and good response to diazoxide treatment (11). Mutations in the GCK gene are a rare cause of $\mathrm{CHI}$, and the clinical presentation varies from a mild phenotype that is responsive to drug treatment to a severe disease (12).

There are two main clinically indistinguishable histological subtypes in CHI: diffuse and focal. Diffuse forms affect all the $\beta$-cells, are genetically heterogeneous, and may be recessively or dominantly inherited. By contrast, focal $\mathrm{CHI}$ is sporadic in inheritance and results from two independent events, a paternally inherited heterozygous mutation in $A B C C 8$ or KCNJ11 and the somatic loss of the maternal allele in the $11 \mathrm{p} 15$ region (loss of heterozygosity) in which only some $\beta$-cells are affected $(6,13)$.

In this paper, we describe the clinical presentation and the molecular genetic characteristics of a group of patients with $\mathrm{CHI}$ in Spain and analyze the data for genotype-phenotype correlations.

\section{Subjects and methods}

\section{Patients}

In this study, we included 50 patients from 47 families (born between 1972 and 2013) referred between January 2005 and September 2013 to the Molecular Genetics Laboratory at BioCruces Health Research Institute (Bizkaia, Spain) for molecular testing of CHI. Patients with $\mathrm{CHI}$ secondary to perinatal stress or associated with syndromic forms were excluded. Biological samples were received from several hospitals across Spain. All families were Spanish Caucasian descent except three families who were of Moroccan, Gambian, and Pakistani descent. Consanguinity was reported in four families. Written informed consent was obtained from all the participants or their parents at each hospital involved in the study. The study was approved by each local ethics committee.

\section{Clinical data}

The clinical diagnosis of $\mathrm{CHI}$ was based on the presence of non-ketotic hypoglycemia with unsuppressed insulin secretion, low free fatty acid levels, and a high glucose requirement to correct hypoglycemia. Clinical data were provided by the clinicians responsible for these patients in their hospitals of origin. The following variables were studied: sex, gestational age, type of delivery, birth weight, age at presentation, type of symptoms, blood test results (glycemia and insulin), treatment received (diet, drug treatment, and surgery), drug doses used, duration of medical treatment, occurrence of adverse effects, and responsiveness to diazoxide treatment. Blood insulin and glucose concentrations were measured simultaneously at the time of hypoglycemia. Response to diazoxide treatment was considered satisfactory if glycemic control was achieved with doses of oral diazoxide lower than $20 \mathrm{mg} / \mathrm{kg} /$ day.

Patients were classified into three groups as a function of age at presentation of hyperinsulinism, assumed to correspond to the onset of clinical signs and symptoms: group $\mathrm{A}$, in the first month of life; group $\mathrm{B}$, between the first month and 2 years of age; and group $C$ from 2 years of age. We calculated the standard deviation scores (SDS) of birth weights considering anthropometric reference data for the Spanish population (14). We considered infants to be large for gestational age if their birth weight was more than 2 SDS above the mean.

\section{Statistical analysis}

IBM SPSS Statistics for Windows (21.0 Version; Armonk, NY, USA) was used for statistical analysis. The independent samples $t$-test was used to compare the means of normally distributed data and the Mann-Whitney U test to compare non-normally distributed data. $\chi^{2}$ or Fisher's exact tests were performed to compare the frequencies of categorical variables. A $P$ value $<0.05$ was considered to be statistically significant.

\section{Genetic analysis}

Genomic DNA was extracted from peripheral blood leukocytes according to the manufacturer's instructions (QIAamp DNA Blood Mini Kit; Qiagen, Germany). Our current routine for new cases with $\mathrm{CHI}$ is to sequence $K C N J 11$ and $A B C C 8$ genes first and, if no mutation is found, GCK gene is sequenced next. Furthermore, the GLUD1 gene is sequenced in patients with hyperammonemia. In patients in whom no mutations were identified, the following genes were also sequenced, depending on the clinical phenotype: HNF4A (13 cases), HNF1A (eight cases), UCP2 (nine cases), and HADH (six cases). 
All promoters, coding exons and intron-exon boundaries of the ABCC8, KCNJ11, GCK, GLUD1, HNF4A, $H N F 1 A$, and $H A D H$ genes were amplified by PCR (primer sequences and conditions are available on request from the authors), purified, bidirectionally sequenced using the Big Dye Terminator v3.1 Cycle Sequencing Kit (Applied Biosystems), and loaded into an ABI 3130xl Genetic Analyzer (Applied Biosystems). The sequences were analyzed and compared with the wild-type published reference sequences (RefSeq) using SeqScape Software v. 2.5 (Applied Biosystems). If applicable, following identification of a mutation in the proband, parents and affected family members were tested to establish the mode of inheritance. For the ABCC 8 gene, the RefSeq used was NM_001287174.1, corresponding to the isoform (1582 amino acids) that incorporates an additional serine residue in exon 17. For the other genes studied, the RefSeqs used were NM_000525.3 for KCNJ11, NM_000162.3 for the pancreatic $\beta$-cell isoform of GCK, NM_005271.3 for GLUD1, NM_175914.4 for HNF4A, NM_000545.5 for HNF1A, and NM_005327.2 for HADH.

Genetic variants were searched against dbSNP, 1000 Genomes, ESP, ExAC, Ensembl, and HGMD databases. The functional consequences of the novel missense variants not listed in these databases were analyzed using in silico prediction tools: MutationTaster (www.mutationtaster.org), PolyPhen-2 (http://genetics.bwh.harvard.edu/pph2/), and SIFT (http://sift-dna.org), whereas for splice site variants we used NNSPLICE (http://www.fruitfly.org/seq_tools/ splice.html), NetGene2 (http://www.cbs.dtu.dk/services/ NetGene2/), and HSF (http://www.umd.be/HSF/). DNA mutations were named in accordance with the Human Genomic Variation Society guidelines.

\section{MLPA analysis}

When sequencing revealed a single heterozygous $A B C C 8$ mutation, or no causative mutation was found in $A B C C 8$ or other genes, the $A B C C 8$ gene was analyzed by multiplex ligation-dependent probe amplification (MLPA). For this, we used the ABCC8 SALSA P117-B1 MLPA kit (MRC Holland, Amsterdam, The Netherlands) as recommended by the manufacturer. In two patients, microsatellite markers across the chromosome 11p15.1$11 \mathrm{p} 15.5$ region were analyzed to search for somatic events (loss of heterozygosity), using DNA extracted from blood and paraffin-embedded pancreatic tissues. Fragments were then separated by capillary electrophoresis (ABI 3130xl Genetic Analyzer) and analyzed using Gene-Mapper, v.4.0 software (Applied Biosystems).

\section{Results}

\section{Clinical characteristics}

In this study, the patient cohort was composed of 50 patients with CHI from Spain. Their general clinical and biochemical characteristics are summarized in Table 1 . Overall, $64 \%$ of patients $(30 / 47)$ responded to diazoxide treatment. The most common adverse effect was hypertrichosis, observed in $28 \%$ of patients. Among the non-responders to diazoxide treatment, 11 patients required pancreatectomy within 1-6 months of age, and these corresponded to eight individuals with $A B C C 8$ mutation and three with an unknown genetic diagnosis.

Group A patients had lower blood glucose levels $(22.2 \pm 10$ vs $36.3 \pm 8.9 \mathrm{mg} / \mathrm{dL} ; P=0.001)$, higher blood insulin levels $(37 \pm 46$ vs $13.5 \pm 11 \mu \mathrm{U} / \mathrm{mL} ; P=0.04)$, and a lower rate of response to diazoxide treatment (44\% $(11 / 25)$ vs $80 \%(16 / 20) ; P=0.018)$ compared with group B patients. The $27 \%$ of group A patients were asymptomatic at diagnosis $(27 \%(7 / 26)$ vs $0 \%(0 / 21)$; $P<0.01)$, hypoglycemia being detected as part of routine monitoring in neonatal care. Furthermore, in group A, a higher percentage of patients developed hypotonia $(46 \%$ $(12 / 26)$ vs $14 \%(3 / 21) ; P=0.02)$ and a lower percentage had convulsions $(19 \%(5 / 26)$ vs $57 \%(12 / 21) ; P=0.014)$ than in group B. No other significant differences were found between the groups.

Table 1 Clinical characteristics of patients with $\mathrm{CHI}$ at diagnosis.

\begin{tabular}{l} 
Clinical characteristics \\
\hline Females, $n$ (\%) \\
Mutation positive, $n$ (\%) \\
Gestational age, weeks (range) \\
Birth weight, $\mathrm{g}$ \\
Large for gestational age, $n$ (\%) \\
Dystocia \\
Age at presentation, $n$ (\%) \\
Within 1 first month of life (group A) \\
Between 1 month and 2 years (group B) \\
From 2 years (group C) \\
Blood glucose, mg/dL \\
Serum insulin, $\mu \mathrm{U} / \mathrm{mL}$ \\
Symptomatology \\
Seizures \\
Hypotonia \\
Loss of consciousness \\
Patients treated with diazoxide, $n$ (\%) \\
Diazoxide dose, mg/kg/day (range) \\
Diazoxide responsive, $n$ (\%)
\end{tabular}

\begin{tabular}{c}
\hline Results $(n=50)$ \\
\hline $32(64 \%)$ \\
$28(56 \%)$ \\
$38 \pm 2.5(31-41)$ \\
$3570 \pm 746$ \\
$17(34 \%)$ \\
$28 \%$ \\
$26(52 \%)$ \\
$21(42 \%)$ \\
$3(6 \%)$ \\
$29 \pm 12$ \\
$26 \pm 37$ \\
$34 \%$ \\
$30 \%$ \\
$28 \%$ \\
$47(94 \%)$ \\
$15 \pm 5.2(7.5-20)$ \\
$30(64 \%)$ \\
\hline
\end{tabular}

Data are mean \pm s.D. or percentage. 


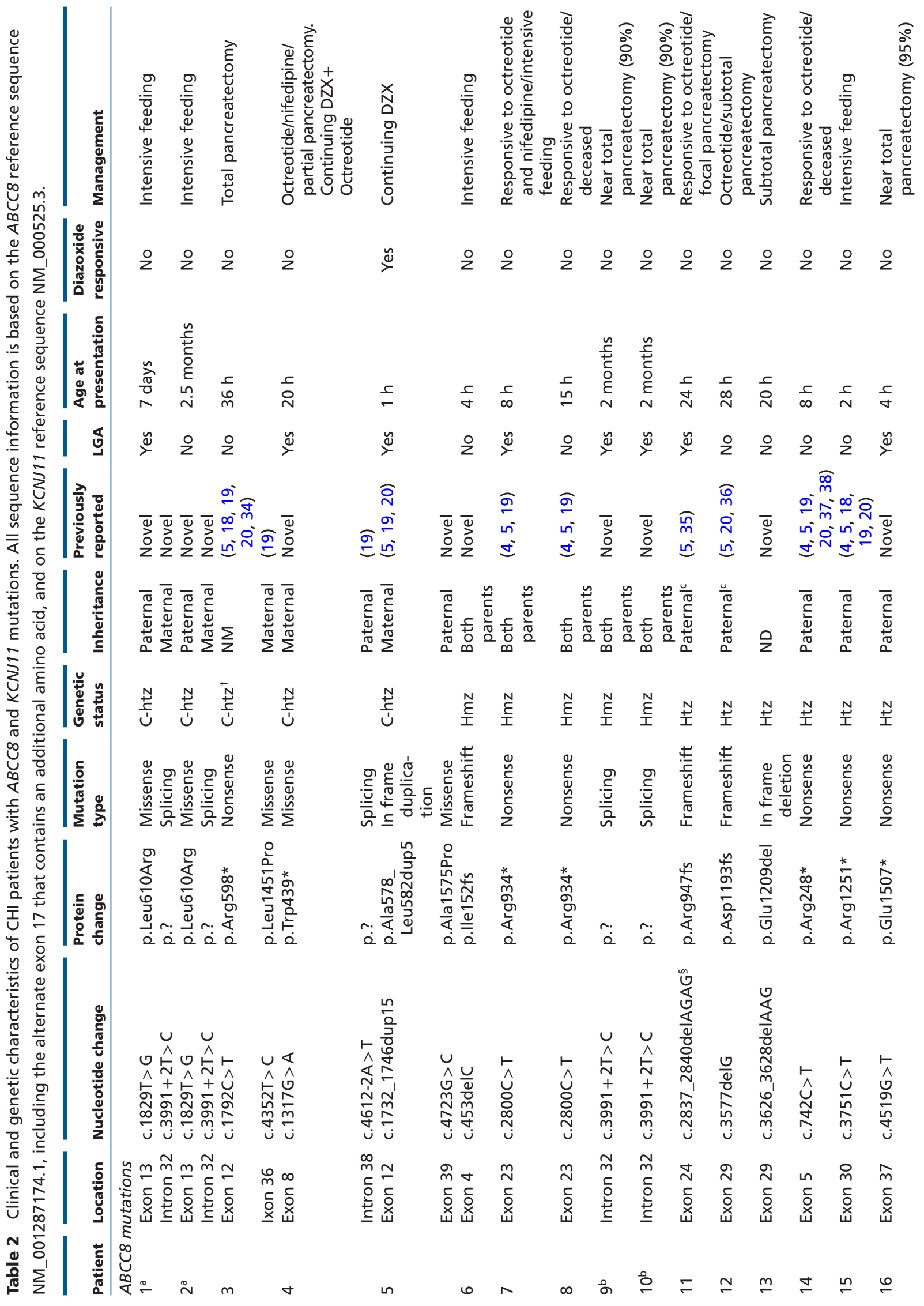




\section{Genetic characteristics}

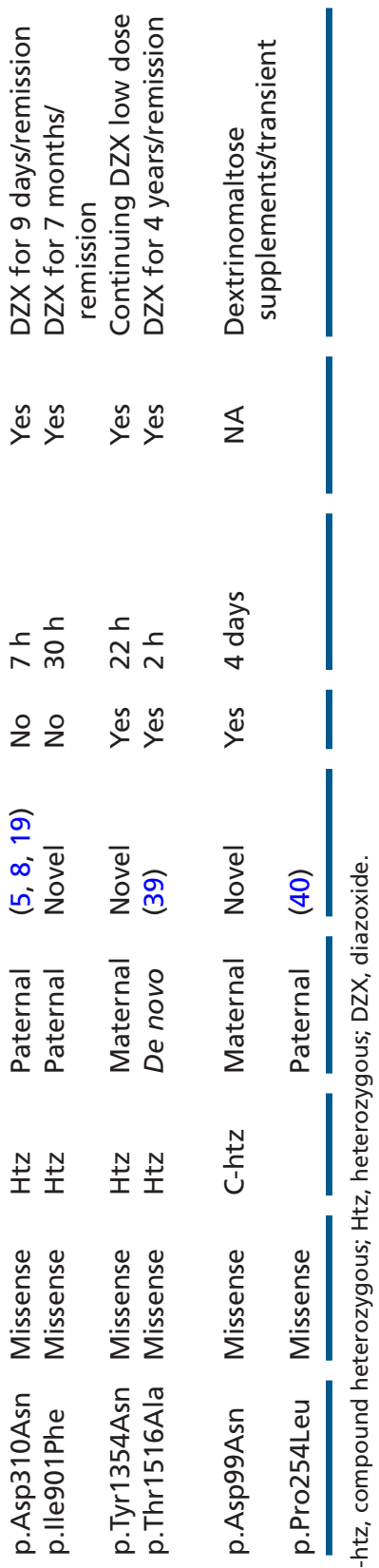

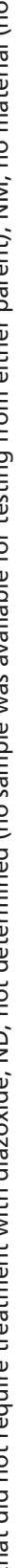

\section{$A B C C 8$ and KCNJ11 mutations}

Considering the 21 out of 50 patients tested (42\%) in whom we identified a $\mathrm{K}_{\text {ATP }}$ channel defect, we found mutations in the $A B C C 8$ gene in all but one case (20/21) (Table 2). In this exception, a patient presenting with transient $\mathrm{CHI}$, we found a compound heterozygous mutation in the KCNJ11 gene, which had been inherited from healthy parents. Altogether, 22 different mutations were identified in the $\mathrm{K}_{\text {ATP }}$ channel genes, among which ten were novel. In silico analysis of these novel mutations predicts a pathogenic effect, as presented in Table 3. These novel mutations were not present in public databases, including the Exome Aggregation Consortium (ExAC) database that has data from more than 60000 individuals (http://exac.broadinstitute.org/). An exception is the splice site mutation c.3991+2T >C in ABCC8 gene, which is present in two $(0.00165 \%)$ of 121178 alleles in ExAC database (in heterozygosis), indicating that this is a very rare variant. This mutation was present in our patients with $\mathrm{CHI}$ in a recessive manner (homozygosis or compound heterozygosis), and the in silico software predicts the loss of the splice site, indicating, as a whole, the pathogenic effect of the variant in a recessive manner.

Complete ABCC 8 sequencing revealed biallelic recessive mutations in ten of the patients. Among them, five had a homozygous mutation (two from consanguineous families) and five a compound heterozygous mutation (Table 2). All these patients inherited the mutations from clinically unaffected parents. Two mutations, the novel splice-donor mutation c. $3991+2 \mathrm{~T}>\mathrm{C}$ and the nonsense mutation p.Arg934*, were each identified in two unrelated families. Only one patient with a biallelic mutation (patient 5) responded to diazoxide treatment.

Single heterozygous mutations in the $A B C C 8$ gene were identified in the other ten patients (Table 2). MLPA of the $A B C C 8$ gene did not disclose any partial or whole gene deletions in these patients. Of these patients, six were unresponsive to diazoxide treatment. Parental samples were available for testing in five cases, all of them showed a paternally inherited mutation from an asymptomatic father. Among them, we only had access to tissue samples in two cases, in which we also 
Table 3 Characteristics and in silico prediction of the deleterious effect of novel mutations detected in patients with $\mathrm{CHI}$. All sequence information is based on the $A B C C 8$ reference sequence NM_001287174.1, including the alternate exon 17 that contains an additional amino acid, on the KCNJ11 reference sequence NM_000525.3, and on the GCK reference sequence NM_000162.3.

\begin{tabular}{|c|c|c|c|}
\hline \multirow[b]{2}{*}{ Gene } & \multicolumn{3}{|c|}{ Mutation } \\
\hline & Nucleotide change & Protein change & Location \\
\hline KCNJ11 & c. $295 \mathrm{G}>\mathrm{A}$ & p.Asp99Asn & Exon 1 \\
\hline$A B C C 8$ & c. 453 delC & p.lle152fs & Exon 4 \\
\hline$A B C C 8$ & c. $1317 \mathrm{G}>\mathrm{A}$ & p. $\operatorname{Trp} 439 *$ & Exon 8 \\
\hline$A B C C 8$ & c. $1829 \mathrm{~T}>\mathrm{G}$ & p.Leu610Arg & Exon 13 \\
\hline$A B C C 8$ & c. $2701 \mathrm{~A}>\mathrm{T}$ & p.lle901Phe & Exon 23 \\
\hline$A B C C 8$ & c.3626_3628delAAG & p.Glu1209del & Exon 29 \\
\hline$A B C C 8$ & c. $4060 \mathrm{~T}>\mathrm{A}$ & p.Tyr1354Asn & Exon 33 \\
\hline$A B C C 8$ & c. $4519 \mathrm{G}>\mathrm{T}$ & p.Glu1507* & Exon 37 \\
\hline$A B C C 8$ & C. $4723 \mathrm{G}>\mathrm{C}$ & p.Ala1575Pro & Exon 39 \\
\hline GCK & c. $297 \mathrm{G}>\mathrm{T}$ & p.Trp99Cys & Exon 3 \\
\hline$A B C C 8$ & c. $3991+2 T>C$ & p.? & Intron 32 \\
\hline
\end{tabular}

\begin{tabular}{|c|c|c|}
\hline \multicolumn{3}{|c|}{ Prediction algorithm } \\
\hline SIFT & PolyPhen-2 & MutationTaster \\
\hline Predict not tolerated & Probably damaging & Disease causing \\
\hline- & - & - \\
\hline- & - & - \\
\hline Predict not tolerated & Probably damaging & Disease causing \\
\hline Predict not tolerated & Possibly damaging & Disease causing \\
\hline- & - & Disease causing \\
\hline Predict not tolerated & Probably damaging & Disease causing \\
\hline- & - & - \\
\hline Predict tolerated & Probably damaging & Disease causing \\
\hline Predict not tolerated & Probably damaging & Disease causing \\
\hline NNSPLICE & NetGene2 & HSF \\
\hline Donor lost & Donor lost & Site broken \\
\hline
\end{tabular}

identified a somatic deletion in the $A B C C 8$ maternal allele in pancreatic tissue, one described as focal (patient 11) and the other, in whom the surgery had been performed in 1997, of unknown form (patient 12). In the four diazoxideresponsive patients, the origins of the mutations were diverse: two of paternal origin (from an asymptomatic father), one of maternal origin, and one de novo. Three patients (patients 17, 18, and 20) had non-permanent CHI requiring diazoxide treatment for a variable period of time ranging from days to 4 years. Patient 20 has progressed to diabetes later. This patient needed diazoxide treatment during the fourth year of age due to recurrent hypoglycemia episodes. Hyperglycemia was observed later because of postprandial glucose controls at home. An OGTT was done and diabetes was diagnosed with $\mathrm{HbA1C}$ levels between 6 and 7\%, negative anti-pancreatic autoantibodies, and normal C-peptide levels. However, patient 19 carrying the unreported p.Tyr1354Asn heterozygous ABCC8 mutation still required diazoxide administration but at low doses and had inherited the mutation from her mother and grandmother, both were diagnosed with diabetes.

\section{GLUD1 and GCK mutations}

In the analysis of GLUD1 gene, dominant missense mutations were identified in three patients who manifested CHI symptoms between 2 and 7 months, had hyperammonemia, and were responsive to diazoxide treatment (Table 4). A de novo mutation had arisen in two cases, and in the other, the mutation had been inherited from an affected mother (the phenotypic characteristics of this patient (patient 23) and his mother have been described previously (15)). Only in two sisters with ammonium levels above $200 \mu \mathrm{mol} / \mathrm{L}$ we have not identified a mutation neither in GLUD1 nor in $H A D H$. We identified four heterozygous missense GCK activating mutations (Table 4), one of which has not previously been reported (Table 3). Only one of these mutations was inherited from an affected mother who had required pancreatectomy, while the affected child had a favorable course. This patient was diagnosed before $24 \mathrm{~h}$ of age; however, the other three were diagnosed after 3 years of age (Table 4), and all responded to diazoxide treatment.

\section{Genotype-phenotype correlation}

In all probands in group A $(n=26)$, the onset of hypoglycemia occurred within the first week after birth. Among this group, 73\% (19/26) of patients had a mutation, all being mutations in the $\mathrm{K}_{\mathrm{ATP}}$ channel genes except one case with a mutation in GCK. Comparing patients with and without a genetic diagnosis, the only statistically significant difference detected was the percentage of patients who were responsive to diazoxide treatment $(33 \%(6 / 18)$ vs $70 \%(5 / 7) ; P<0.01)$.

In group B $(n=21), 28.6 \%$ of patients $(n=6)$ had a genetic diagnosis. Three of them were found to have a GLUD1 mutation and the other three an ABCC8 mutation, with an age of 4.8 months and 2 months, respectively, at $\mathrm{CHI}$ diagnosis. Patients with an unknown genetic diagnosis $(71.4 \%, 15 / 21)$ presented with signs and symptoms of $\mathrm{CHI}$ at $8 \pm 3.8$ months of age and the majority (87\%) responded to diazoxide treatment.

In group $\mathrm{C}$, all the three cases had a GCK mutation. Their clinical characteristics were very different, with mild symptomatology and moderate hypoglycemia, and 
Table 4 Clinical and genetic characteristics of $\mathrm{CHI}$ patients with dominant GLUD1 and GCK mutations. All sequence information is based on the GLUD1 reference sequence NM_005271.3, with nucleotide and amino acid numbers starting with the A of the ATG initiation codon. (In parentheses, the mutation is described with amino acid numbers beginning at the start of the mature protein, as is widely used in the literature.) The GCK sequence information is based on reference sequence NM_000162.3.

\begin{tabular}{|c|c|c|c|c|c|c|c|c|c|c|}
\hline Patient & Gene & Location & $\begin{array}{l}\text { Nucleotide } \\
\text { change }\end{array}$ & Protein change & $\begin{array}{l}\text { Mutation } \\
\text { type }\end{array}$ & $\begin{array}{l}\text { Genetic } \\
\text { status }\end{array}$ & Inheritance & $\begin{array}{l}\text { Age at } \\
\text { presentation }\end{array}$ & Management & Described \\
\hline 22 & GLUD1 & Exon 6 & c. $820 \mathrm{C}>\mathrm{T}$ & $\begin{array}{l}\text { p.Arg274Cys } \\
\text { (p.Arg221Cys) }\end{array}$ & Missense & $\mathrm{Htz}$ & De novo & 7 months & $\begin{array}{l}\text { DZX/continuing } \\
\text { with frequent } \\
\text { feeding }\end{array}$ & $(5,11,32)$ \\
\hline 23 & GLUD1 & Exon 7 & c. $965 G>A$ & $\begin{array}{l}\text { p.Arg322His } \\
\text { (p.Arg269His) }\end{array}$ & Missense & $\mathrm{Htz}$ & Maternal & 6 months & $\begin{array}{l}\text { Continuing } \\
\text { DZX }\end{array}$ & $(5,11,32)$ \\
\hline 24 & GLUD1 & Exon 11 & c. $1493 C>T$ & $\begin{array}{l}\text { p.Ser498Leu } \\
\text { (p.Ser445Leu) }\end{array}$ & Missense & $\mathrm{Htz}$ & De novo & 2 months & $\begin{array}{l}\text { Continuing } \\
\text { DZX }\end{array}$ & $(5,32,33)$ \\
\hline 25 & GCK & Exon 2 & c. $194 C>T$ & p.Thr65lle & Missense & $\mathrm{Htz}$ & De novo & 3.7 years & $\begin{array}{l}\text { Continuing } \\
\text { DZX }\end{array}$ & (30) \\
\hline 26 & GCK & Exon 3 & c. $271 \mathrm{G}>\mathrm{T}$ & p.Val91Leu & Missense & $\mathrm{Htz}$ & Maternal & $20 \mathrm{~h}$ & $\begin{array}{l}\text { Continuing } \\
\text { DZX }\end{array}$ & (41) \\
\hline 27 & GCK & Exon 3 & c. $297 \mathrm{G}>\mathrm{T}$ & p.Trp99Cys & Missense & $\mathrm{Htz}$ & NM & 25 years & $\begin{array}{l}\text { DZX/continuing } \\
\text { with frequent } \\
\text { feeding }\end{array}$ & Novel \\
\hline 28 & GCK & Exon 10 & c. $1324 G>A$ & p.Glu442Lys & Missense & $\mathrm{Htz}$ & Paternal & 5 years & $\begin{array}{l}\text { DZX/lanreotide } \\
\text { continuing } \\
\text { DZX }\end{array}$ & $(42)$ \\
\hline
\end{tabular}

Htz, heterozygous; DZX, diazoxide; NM, no material (no samples were available for testing).

therefore, the diagnosis was made even years after the onset of the signs and symptoms of CHI.

Patients with mutations in the $\mathrm{K}_{\mathrm{ATP}}$ channel genes were diagnosed earlier $(10.7 \pm 22.8$ vs $164 \pm 148$ days; $P<0.01)$, had lower blood glucose levels $(20.4 \pm 8.8$ vs $33.7 \pm 11 \mathrm{mg} / \mathrm{dL} ; \quad P<0.01)$, required higher doses of diazoxide $(18.5 \pm 10.9$ vs $12.2 \pm 5.6 \mathrm{mg} / \mathrm{kg} /$ day; $P<0.01)$, and had lower rates of treatment success $(25 \%(5 / 20)$ vs $86 \%(19 / 22) ; P<0.01)$ than those without a genetic diagnosis.

\section{Discussion}

CHI is clinically and genetically a heterogeneous disease with transient and persistent forms. In our study, a genetic diagnosis was obtained in $56 \%$ of patients with $\mathrm{CHI}$ tested, similar to figures reported in other studies $(4,16$, $17,18)$, although slightly lower than that found in the only previous study in a Spanish population (19). ABCC8 inactivating mutations are the leading genetic cause of CHI in our patients. This study has identified ten novel mutations in the $\mathrm{K}_{\mathrm{ATP}}$ channel genes.

Clinically, we found that patients with $\mathrm{CHI}$ secondary to the $\mathrm{K}_{\mathrm{ATP}}$ channel gene mutations had more severe disease, in line with other data in the literature (6). They had an earlier onset of signs and symptoms, a greater degree of hypoglycemia, and a lower rate of response to treatment.

The likelihood of finding genetic alterations decreases with age at presentation and is lower among individuals who respond to treatment, as has been reported recently $(4,5,20)$. These trends could be explained by the existence of alterations in genes related to $\mathrm{CHI}$ that are not known yet and that could cause milder types of hypoglycemia than the currently identified genes. Another possibility is that a burden of hypomorphic mutations or rare variants in several genes could predispose to hyperinsulinism in an individual and may have a role in leading to less severe disease and contribute to the etiology of CHI.

It has been described that hypoglycemia may resolve in as many as a half of newly diagnosed children with $\mathrm{CHI}$ (21). A lack of known mutations seems to make remission more likely, ranging from $44 \%$ in an Italian cohort (17) to $88 \%$ in the study by Banerjee et al. (21), and to date $41 \%$ have remitted in our series. The variation in the rate may be due to the different follow-up periods across the series. In any case, we should not suspect an incorrect diagnosis, as remission is possible in a variable period of time in individuals with genetic alterations.

In our cohort, half of the patients with $A B C C 8$ mutations had a biallelic mutation, had a severe phenotype, and did not respond to diazoxide treatment, as has been described in the literature $(4,5,20)$. An exception within this group is the patient with compound heterozygous mutation in ABCC8 (patient 5) who did respond to diazoxide treatment. This patient had a p.Ala578_Leu582dup mutation in the paternal allele, a mutation that has been described to be associated with different situations in two patients with 
the mutation in heterozygosis and paternally inherited, who had a severe phenotype and did not respond to diazoxide treatment $(5,20)$, and in one patient with a compound heterozygous mutation, who was managed with continuous feeding (19). In the maternal allele, our patient has a novel missense mutation p.Ala1575Pro, and in silico analysis showed discrepant results (Table 3). Although the majority of biallelic mutations result in diazoxide-unresponsive $\mathrm{CHI}$, some cases have been described with compound heterozygous mutations associated with a diazoxide-responsive CHI $(22,23,24)$.

We identified ten heterozygous ABCC 8 mutations. These patients had a mixed phenotype. Arya et al. (24) recently evaluated a cohort of $\mathrm{CHI}$ patients with paternally inherited heterozygous $A B C C 8$ mutations, highlighting the clinical and histological heterogeneity of this type of CHI. We showed seven patients to have paternally inherited heterozygous mutations from an asymptomatic father. Of them, four were pancreatectomized but only one was reported to have focal hyperinsulinism. Paternally inherited monoallelic mutations may be recessively associated with somatic loss of the maternal $11 \mathrm{p}$ allele linked to a focal CHI, but also with a dominant mutation and diffuse disease.

We found four patients with $A B C C 8$ heterozygous mutations and diazoxide-responsive $\mathrm{CHI}$, suggestive of a dominant mutation. Two patients inherited the mutation from an unaffected father, one of these patients having the p.Asp310Asn mutation that Pinney et al. (7) reported to cause mild, dominantly inherited $\mathrm{CHI}$ and having been also inherited from an asymptomatic father. A variable penetrance in dominant mutations has been described previously $(7,9,10,25,26)$, with adult carriers of a dominant mutation often being asymptomatic. In three patients with ABCC8 heterozygous mutations who were responsive to diazoxide treatment, the hyperinsulinism resolved after several months. The transient nature of $\mathrm{CHI}$ in these patients agrees with previous reports (10, $17,21)$. Of these patients, one (patient 20) had transient hypoglycemia that progressed to diabetes later in childhood. Another interesting case is the patient with the novel heterozygous ABCC8 mutation p.Tyr1354Asn (patient 19), who inherited the mutation from her mother and grandmother, both of whom were diagnosed with diabetes. Progression from hypoglycemia to diabetes has been reported by others authors $(8,10)$ and has been observed in long-term follow-up of non-pancreatectomized $\mathrm{CHI}$ patients with mutations in $A B C C 8$ (27). Furthermore, various authors have observed diabetes in adult $A B C C 8$ mutation carriers $(8,10)$; however, it remains unclear whether these dominant $A B C C 8$ gene mutations predispose individuals to diabetes mellitus in adulthood (7). The first dominant heterozygous inactivating ABCC8 mutation reported, causing a mild form of $\mathrm{CHI}$, was p.Glu1506Lys (p.Glu1507Lys according to reference sequence NM_001287174.1); the authors also reported a loss of insulin secretory capacity in early adulthood and an increased risk of diabetes in middle age in adult carriers (8). This mutation has also been reported in a Brazilian family with $\mathrm{CHI}$ in childhood, which developed gestational diabetes, glucose intolerance, and diabetes in adulthood (28). Kapoor et al. (10) have shown a progression from hypoglycemia to diabetes later in life in two individuals with $A B C C 8$ dominant mutations, p.Gly1479Arg and p.Ala1508Pro, but also gestational diabetes or diabetes in ABCC8 mutation carriers (p.Ala1537Val, p.Gln1459Glu, p.Leu1431Phe, and p.Ala1508Pro). However, it is also clear that not all adult mutation carriers develop diabetes, as was reported in the study of Pinney et al. (7), in which from 16 families with dominant $A B C C 8$ mutations, only $4 / 29$ adults had diabetes. Recently, it has been observed in $\mathrm{CHI}$ mouse model that the homE1506K mutation in $\mathrm{Abcc8}$ showed an increased insulin secretion in early life, but reduced secretion later, similar to heterozygous patients with this mutation (29).

The finding of mutations in $83 \%$ of patients who did not respond to diazoxide treatment in this series is similar to the pattern reported by other authors $(4,5$, 17). However, we would like to emphasize that unlike the widely held belief of non-responsiveness, some carriers of the $\mathrm{K}_{\text {ATP }}$ channel mutations do respond to diazoxide treatment and can even show spontaneous remission, as mentioned earlier.

In our series, activating mutations in the GCK gene are the second cause of $\mathrm{CHI}$, and the severity of symptoms and age at presentation vary significantly among the affected individuals, even within the same family. In this sense, our sample generally corroborates what is described in the literature $(12,30,31)$. The three patients in our series with dominant mutations in GLUD1 had moderate hyperinsulinism together with hyperammonemia, normal birth weight, median age of onset of 5 months, and were responsive to diazoxide treatment, similar to other reported cases $(11,32,33)$.

A limitation of this study is that patients were diagnosed and treated at different institutions, as this may have affected the uniformity of assessment data and criteria for the treatment of $\mathrm{CHI}$.

In conclusion, genetic analysis revealed a mutation in $56 \%$ of patients. Mutations in ABCC8 are the most 
common cause of $\mathrm{CHI}$ in Spain. However, the number of cases of $\mathrm{CHI}$ with no genetic diagnosis remains high, presenting a challenge for research in molecular genetics and new sequencing technologies. In this study, we present ten patients with mutations not previously described and some cases with a non-classical clinical course, demonstrating the complexity and heterogeneous nature of hyperinsulinism.

\section{Declaration of interest}

The authors declare that there is not conflict of interest that could be perceived as prejudicing the impartiality of the research reported.

\section{Funding}

This work was supported in part by grants from the Department of Health of the Basque Government (GV2010/111185) and the University of the Basque Country UPV/EHU (IT795-13). TV is supported by a personal research fellowship from the researcher training (FPI) program of the University of the Basque Country (IF/UPV12/135).

\section{Acknowledgements}

The authors thank all the members of the affected families for their collaborative participation in this study. They also thank A Etxaniz and G Pérez-Nanclares for technical assistance.

The members of the Spanish Congenital Hyperinsulinism Group include the following individuals and institutions: Hospital Universitario (H.U.) Marqués de Valdecilla, Santander (C Luzuriaga); H.U. General de Albacete (R Ruiz); H.U. Miguel Servet, Zaragoza (G M Lou); H.U. Valme, Sevilla (R Espino); H.U. Son Espases, Palma Mallorca (M Caimari); H.U. del Mar, Barcelona (M Bonet); H.U. Virgen Rocío, Sevilla (A L Gómez-Gila); H. de Mérida, Badajoz (M Fernández-Burriel); H.U. Reina Sofía, IMIBIC, Universidad de Córdoba, Córdoba (M Gil-Campos); H.U. Germans Trias i Pujol, Badalona, Barcelona (M Murillo); H.U. Regional Málaga, Málaga (J P López-Siguero); H.U. Vall d' Hebron, Barcelona (M Clemente); H.U. La Fe, Valencia (M F Moreno); H. General de Granollers, Barcelona (M V Borras); H.U. Alcalá de Henares Príncipe de Asturias, Madrid (J Ramírez); H.U. Rafael Méndez, Lorca, Murcia (M J Romero); H.U. Príncipe de Asturias, Alcalá de Henares, Madrid (C Blanco); Instituto de Investigación i+12, H.U. 12 de OctubreCIBERER Grupo U723, Madrid (M T García-Silva); H.U. Cruces, Barakaldo (A Rodriguez), H.U. Getafe, Madrid (B Sagastizabal); H.U. Virgen de la Arrixaca, Murcia (J M Martos); Instituto de Investigación Sanitaria BioCruces-H.U. Cruces, Barakaldo (M Ortiz-Espejo, I Martínez de LaPiscina and G Pérez-Nanclares); and H.U. Ramón y Cajal, Madrid (M Martínez-Pardo).

\section{References}

1 Kapoor RR, Flanagan SE, James C, Shield J, Ellard S \& Hussain K. Hyperinsulinaemic hypoglycaemia. Archives of Disease in Childhood 200994 450-457. (doi:10.1136/adc.2008.148171)

2 Rahman SA, Nessa A \& Hussain K. Molecular mechanisms of congenital hyperinsulinism. Journal of Molecular Endocrinology 2015 54 R119-R129. (doi:10.1530/JME-15-0016)

3 Arnoux JB, Verkarre V, Saint-Martin C, Montravers F, Brassier A, Valayannopoulos V, Brunelle F, Fournet JC, Robert JJ, Aigrain Y et al. Congenital hyperinsulinism: current trends in diagnosis and therapy. Orphanet Journal of Rare Diseases 20116 63. (doi:10.1186/1750-1172-6-63)

4 Kapoor RR, Flanagan SE, Arya VB, Shield JP, Ellard S \& Hussain K. Clinical and molecular characterisation of 300 patients with congenital hyperinsulinism. European Journal of Endocrinology 2013 168 557-564. (doi:10.1530/EJE-12-0673)

5 Snider KE, Becker S, Boyajian L, Shyng SL, MacMullen C, Hughes N, Ganapathy K, Bhatti T, Stanley CA \& Ganguly A. Genotype and phenotype correlations in 417 children with congenital hyperinsulinism. Journal of Clinical Endocrinology \& Metabolism 2013 98 E355-E363. (doi:10.1210/jc.2012-2169)

6 Lord K \& De León DD. Monogenic hyperinsulinemic hypoglycemia: current insights into the pathogenesis and management. International Journal of Pediatric Endocrinology 20132013 3. (doi:10.1186/16879856-2013-3)

7 Pinney SE, MacMullen C, Becker S, Lin YW, Hanna C, Thornton P, Ganguly A, Shyng SL \& Stanley CA. Clinical characteristics and biochemical mechanisms of congenital hyperinsulinism associated with dominant KATP channel mutations. Journal of Clinical Investigation 2008118 2877-2886. (doi:10.1172/JCI35414)

8 Huopio H, Otonkoski T, Vauhkonen I, Reimann F, Ashcroft F \& Laakso M. A new subtype of autosomal dominant diabetes attributable to a mutation in the gene for the sulphonylurea receptor 1 . Lancet 2003361 301-307. (doi:10.1016/S0140-6736(03)12325-2)

9 Macmullen CM, Zhou Q, Snider KE, Tewson PH, Becker SA, Aziz AR, Ganguly A, Shyng SL \& Stanley CA. Diazoxide-unresponsive congenital hyperinsulinism in children with dominant mutations of the $\beta$-cell sulfonylurea receptor SUR1. Diabetes 201160 1797-1804. (doi:10.2337/db10-1631)

10 Kapoor RR, Flanagan SE, James CT, McKiernan J, Thomas AM, Harmer SC, Shield JP, Tinker A, Ellard S \& Hussain K. Hyperinsulinaemic hypoglycaemia and diabetes mellitus due to dominant ABCC8/KCNJ11 mutations. Diabetologia 201154 2575-2583. (doi:10.1007/s00125-011-2207-4)

11 Kapoor RR, Flanagan SE, Fulton P, Chakrapani A, Chadefaux B, Ben-Omran T, Banerjee I, Shield JP, Ellard S \& Hussain K. Hyperinsulinism-hyperammonaemia syndrome: novel mutations in the GLUD1 gene and genotype-phenotype correlations. European Journal of Endocrinology 2009161 731-735. (doi:10.1530/EJE-090615)

12 Cuesta-Muñoz AL, Huopio H, Otonkoski T, Gomez-Zumaquero JM, Näntö-Salonen K, Rahier J, López-Enriquez S, García-Gimeno MA, Sanz P, Soriguer FC et al. Severe persistent hyperinsulinemic hypoglycemia due to a de novo glucokinase mutation. Diabetes $\mathbf{2 0 0 4}$ 53 2164-2168. (doi:10.2337/diabetes.53.8.2164)

13 Arnoux JB, de Lonlay P, Ribeiro MJ, Hussain K, Blankesnstein O, Mohnike K, Valayannopoulos V, Robert JJ, Rahier J, Sempoux C et al. Congenital Hyperinsulinism. Early Human Development 201086 287-294. (doi:10.1016/j.earlhumdev.2010.05.003)

14 Carrascosa A, Ferrández A, Yeste D, García-Dihinx J, Romo A, Copil A, Almar J, Salcedo S, Gussinyé M \& Baguer L. Spanish cross-sectional growth study 2008. Part I: weight and height values in newborns of 26-42 weeks of gestational age. An Pediatr (Barc) 200868 544-551. (doi:10.1157/13123286)

15 de las Heras J, Garin I, de Nanclares GP, Aguayo A, Rica I, Castaño L \& Vela A. Familial hyperinsulinism-hyperammonemia syndrome in a family with seizures: case report. Journal of Pediatric Endocrinology and Metabolism 201023 827-830. (doi:10.1515/jpem.2010.132)

16 Faletra F, Athanasakis E, Morgan A, Biarnés X, Fornasier F, Parini R, Furlan F, Boiani A, Maiorana A, Dionisi-Vici C et al. Congenital hyperinsulinism: clinical and molecular analysis of a large Italian cohort. Gene 2013521 160-165. (doi:10.1016/j.gene.2013.03.021)

17 Sogno Valin P, Proverbio MC, Diceglie C, Gessi A, di Candia S, Mariani B, Zamproni I, Mangano E, Asselta R, Battaglia C et al. Genetic analysis of Italian patients with congenital hyperinsulinism of infancy. Hormone Research in Paediatrics 201379 236-242. (doi:10.1159/000350827)

18 Mohnike K, Wieland I, Barthlen W, Vogelgesang S, Empting S, Mohnike W, Meissner T \& Zenker M. Clinical and genetic evaluation of patients with $\mathrm{K}_{\mathrm{ATP}}$ channel mutations from the German registry for 
congenital hyperinsulinism. Hormone Research in Paediatrics 201481 156-168. (doi:10.1159/000356905)

19 Fernández-Marmiesse A, Salas A, Vega A, Fernández-Lorenzo JR, Barreiro J \& Carracedo A. Mutation spectra of ABCC8 gene in Spanish patients with Hyperinsulinism of Infancy (HI). Human Mutation 2006 27 214. (doi:10.1002/humu.9401)

20 Bellanné-Chantelot C, Saint-Martin C, Ribeiro MJ, Vaury C, Verkarre V, Arnoux JB, Valayannopoulos V, Gobrecht S, Sempoux C, Rahier J et al. ABCC8 and KCNJ11 molecular spectrum of 109 patients with diazoxide-unresponsive congenital hyperinsulinism. Journal of Medical Genetics 201047 752-759. (doi:10.1136/jmg.2009.075416)

21 Banerjee I, Skae M, Flanagan SE, Rigby L, Patel L, Didi M, Blair J, Ehtisham S, Ellard S, Cosgrove KE et al. The contribution of rapid KATP channel gene mutation analysis to the clinical management of children with congenital hyperinsulinism. European Journal of Endocrinology 2011164 733-740. (doi:10.1530/EJE-10-1136)

22 Dekel B, Lubin D, Modan-Moses D, Quint J, Glaser B \& Meyerovitch J. Compound heterozygosity for the common sulfonylurea receptor mutations can cause mild diazoxide-sensitive hyperinsulinism. Clinical Pediatrics 200241 183-186. (doi:10.1177/000992280204100310)

23 Kumaran A, Kapoor RR, Flanagan SE, Ellard S \& Hussain K. Congenital hyperinsulinism due to a compound heterozygous ABCC8 mutation with spontaneous resolution at eight weeks. Hormone Research in Paediatrics 201073 287-292. (doi:10.1159/000284394)

24 Arya VB, Aziz Q, Nessa A, Tinker A \& Hussain K. Congenital hyperinsulinism: clinical and molecular characterisation of compound heterozygous ABCC8 mutation responsive to Diazoxide therapy. International Journal of Pediatric Endocrinology 2014201424. (doi:10.1186/1687-9856-2014-24)

25 Shemer R, Avnon Ziv C, Laiba E, Zhou Q, Gay J, Tunovsky-Babaey S, Shyng SL, Glaser B \& Zangen DH. Relative expression of a dominant mutated ABCC8 allele determines the clinical manifestation of congenital hyperinsulinism. Diabetes 201261 258-263. (doi:10.2337/ db11-0984)

26 Nessa A, Aziz QH, Thomas AM, Harmer SC, Tinker A \& Hussain K. Molecular mechanisms of congenital hyperinsulinism due to autosomal dominant mutations in ABCC8. Human Molecular Genetics 201524 5142-5153. (doi:10.1093/hmg/ddv233)

27 Gussinyer M, Clemente M, Cebrián R, Yeste D, Albisu M \& Carrascosa A. Glucose intolerance and diabetes are observed in the long-term follow-up of nonpancreatectomized patients with persistent hyperinsulinemic hypoglycemia of infancy due to mutations in the ABCC8 gene. Diabetes Care 200831 1257-1259. (doi:10.2337/dc07-2059)

28 Vieira TC, Bergamin CS, Gurgel LC \& Moisés RS. Hyperinsulinemic hypoglycemia evolving to gestational diabetes and diabetes mellitus in a family carrying the inactivating ABCC8 E1506K mutation. Pediatric Diabetes 201011 505-508. (doi:10.1111/ pdi.2010.11.issue-7)

29 Shimomura K, Tusa M, Iberl M, Brereton MF, Kaizik S, Proks P, Lahmann C, Yaluri N, Modi S, Huopio H et al. A mouse model of human hyperinsulinism produced by the E1506K mutation in the sulphonylurea receptor SUR1. Diabetes 201362 3797-3806. (doi:10.2337/db12-1611)

30 Gloyn AL, Noordam K, Willemsen MA, Ellard S, Lam WW, Campbell IW, Midgley P, Shiota C, Buettger C, Magnuson MA et al. Insights into the biochemical and genetic basis of glucokinase activation from naturally occurring hypoglycemia mutations. Diabetes 200352 2433-2440. (doi:10.2337/diabetes.52.9.2433)
31 Hussain K. Mutations in pancreatic B-cell Glucokinase as a cause of hyperinsulinaemic hypoglycaemia and neonatal diabetes mellitus. Reviews in Endocrine and Metabolic Disorders 201011 179-183. (doi:10.1007/s11154-010-9147-z)

32 Santer R, Kinner M, Passarge M, Superti-Furga A, Mayatepek E, Meissner T, Schneppenheim R \& Schaub J. Novel missense mutations outside the allosteric domain of glutamate dehydrogenase are prevalent in European patients with the congenital hyperinsulinismhyperammonemia syndrome. Human Genetics 2001108 66-71. (doi:10.1007/s004390000432)

33 Stanley CA, Lieu YK, Hsu BY, Burlina AB, Greenberg CR, Hopwood NJ, Perlman K, Rich BH, Zammarchi E \& Poncz M. Hyperinsulinism and hyperammonemia in infants with regulatory mutations of the glutamate dehydrogenase gene. New England Journal of Medicine 1998 338 1352-1357. (doi:10.1056/NEJM199805073381904)

34 Suchi M, MacMullen C, Thornton PS, Ganguly A, Stanley CA \& Ruchelli ED. Histopathology of congenital hyperinsulinism: retrospective study with genotype correlations. Pediatric and Developmental Pathology 20036 322-333. (doi:10.1007/s10024-0020026-9)

35 Stanley CA, Thornton PS, Ganguly A, MacMullen C, Underwood P, Bhatia P, Steinkrauss L, Wanner L, Kaye R, Ruchelli E et al. Preoperative evaluation of infants with focal or diffuse congenital hyperinsulinism by intravenous acute insulin response tests and selective pancreatic arterial calcium stimulation. Journal of Clinical Endocrinology \& Metabolism 200489 288-296. (doi:10.1210/jc.2003-030965)

36 Greer RM, Shah J, Jeske YW, Brown D, Walker RM, Cowley D, Bowling FG, Liaskou D, Harris M, Thomsett MJ et al. Genotypephenotype associations in patients with severe hyperinsulinism of infancy. Pediatric and Developmental Pathology 200710 25-34. (doi:10.2350/06-04-0083.1)

37 Aguilar-Bryan L \& Bryan J. Molecular biology of adenosine triphosphate-sensitive potassium channels. Endocrine Reviews 199920 101-135. (doi:10.1210/edrv.20.2.0361)

38 Sandal T, Laborie LB, Brusgaard K, Eide SA, Christesen HB, Søvik O, Njølstad PR \& Molven A. The spectrum of ABCC8 mutations in Norwegian patients with congenital hyperinsulinism of infancy. Clinical Genetics $2009 \mathbf{7 5} 440-448$. (doi:10.1111/cge.2009.75.issue-5)

39 Bennett JT, Vasta V, Zhang M, Narayanan J, Gerrits P \& Hahn SH. Molecular genetic testing of patients with monogenic diabetes and hyperinsulinism. Molecular Genetics and Metabolism 2015114 451-458. (doi:10.1016/j.ymgme.2014.12.304)

40 Tornovsky S, Crane A, Cosgrove KE, Hussain K, Lavie J, Heyman M, Nesher Y, Kuchinski N, Ben-Shushan E, Shatz O et al. Hyperinsulinism of infancy: novel ABCC8 and KCNJ11 mutations and evidence for additional locus heterogeneity. Journal of Clinical Endocrinology \& Metabolism 200489 6224-6234. (doi:10.1210/jc.2004-1233)

41 Kassem S, Bhandari S, Rodríguez-Bada P, Motaghedi R, Heyman M, García-Gimeno MA, Cobo-Vuilleumier N, Sanz P, Maclaren NK, Rahier J et al. Large islets, beta-cell proliferation, and a glucokinase mutation. New England Journal of Medicine 2010362 1348-1350. (doi:10.1056/NEJMc0909845)

42 Barbetti F, Cobo-Vuilleumier N, Dionisi-Vici C, Toni S, Ciampalini P, Massa O, Rodriguez-Bada P, Colombo C, Lenzi L, Garcia-Gimeno MA et al. Opposite clinical phenotypes of glucokinase disease: description of a novel activating mutation and contiguous inactivating mutations in human glucokinase (GCK) gene. Molecular Endocrinology 200923 1983-1989. (doi:10.1210/me.2009-0094)

Received 11 January 2016

Revised version received 2 March 2016

Accepted 7 March 2016 